\title{
LA REVISION POR LAS CORPORACIONES LOCALES DE LOS ACTOS ADMINISTRATIVOS, SUSCEPTIBLES DE NULIDAD, QUE HAYAN ADOPTADO
}

35.076: 352

por

\section{Sabino Alvarez-Gendín y Blanco}

Catedrático de Derecho administrativo

SUMARIO: I. PUNTO DE VISTA JURIDICO DE LA REVISION ADMINISTRATIVA DE LOS ACTOS DE LA ADMINISTRACION LOCAL.II. PUNTO DE VISTA POLITICO DE LA REVISION ADMINISTRATIVA DE LOS ACTOS DE LA ADMINISTRACION LOCAL.

I. PUNTO DE VISTA JURIDICO DE LA REVISION ADMINISTRATIVA DE LOS ACTOS DE LA ADMINISTRACION LOCAL

Con un espíritu jurídico bien intencionado, el competente catedrático de la Universidad de Bilbao, MARTf́n MATEo, pretende homologar la Administración local a la Administración central, en punto a revisar de oficio los actos susceptibles de nulidad de la esfera local, en un artículo que intitula de semejante jaez en la REvista DE Estudios dE LA Vida Local (número 182, abril-junio 1974, páginas 9, 11 y siguientes), tomando como argumento el artículo 109 en relación con el 47 de la Ley de Procedimiento, que tiene su antecedente en el 37 de la Ley de Régimen jurídico del Estado, 
pudiendo anularlo ex tune administrativamente, es decir, sin previa declaración de lesividad del acto que se estime dictado irregularmente para acudir a la vía contencioso-administrativa a fin de que el Tribunal pertinente se pronuncie en este sentido.

El artículo 369 de la Ley de Régimen local dice terminantemente: "Las Autoridades y Corporaciones locales no podrán revocar sus propios actos o acuerdos declaratorios de derechos sub. jetivos o que hubieran servido de base a una resolución judicial, salvo al resolver récursos de reposición. Podrán, sin embargo, rectificar los errores materiales de hecho.»

¿La Ley de Procedimiento administrativo será supletoria de las normas que regulan el procedimiento administrativo de las Corporaciones locales y de los organismos autónomos en materia de revisión administrativa de sus propios actos nulos? De estos organismos sí tendrá validez la revisión de oficio, puesto que no hay normas especiales que regulen la cuestión como en la Administración local (II), ello de acuerdo con el artículo $1 .^{\circ}, 4$, de la Ley de Procedimiento administrativo.

Por lo que respecta al vigor del artículo 76, 1, del Decreto-ley de Régimen especial de Madrid de 11 de julio de 1963 -autorizado a sancionarlo al Poder ejecutivo por la Ley de 7 de noviembre de 1957-, que dice en los casos y formas que establece la Ley de Procedimiento administrativo, podrá el Ayuntamiento pleno declarar la nulidad cuando infrinjan manifiestamente la Ley los actos y acuerdos declarativos de derechos dictados por cualquiera de los órganos del Municipio", nosotros estimamos su carencia, pues el artículo lo consideramos ilegal, por contradecir la Base 56, párrafo final (1), de la Ley de 17 de julio de 1945, de Régimen local, en la que tuvo asiento el enunciado artículo 369 del Decreto legislativo de 16 de octubre de 1950, ratificado en el de 24 de junio de 1955, pues no estaba autorizada la prerrogativa de modificar dicha Base 56 por la Ley citada de 1957 de autorización para dictar las leyes especiales de Madrid y Barcelona, no sólo porque doctrinalmente se viene estimando el rango superior de la ley, derogable sólo por otra posterior (artículo 5 del Código Civil), sino

(1) Dice así dicho párrafo: «Las Autoridades y Corporaciones locales no podrán revocar sus propios actos o acuerdos declaratorios de derechos subjetivos o que hubieran servido de base a una resolución judicial, salvo al decidir recursos de reposición o rectificando errores materiales de hecho.» 
porque la propia Ley de Régimen jurídico, aludida, prohibía a la Administración dictar disposiciones contrarias a leyes —en sentido formal y material-, que por su mayor rango no puede alterarlas (artículo 17 del Fuero de los Españoles), bajo sanción de plena nulidad (artículo 28, Ley de Régimen jurídico de la Administración del Estado), siendo responsables civil y penalmente los magistrados del Tribunal Contencioso-administrativo que aplicasen al acto administrativo nulo ejecutorio de la Ley especial que infringe al artículo 369 de la Ley de Régimen local, sustentado en la Base 56 de la Ley de 17 de julio de 1945 (artículo 8 de la Ley Orgánica del Poder judicial), salvo autorización expresa de otra ley, previo dictamen del Consejo de Estado en pleno (artículo 104, Ley de Régimen jurídico de la Administración del Estado y 51, Ley Orgánica del Estado) (2), en materia que sea de la exclusiva competencia de las Cortes, como son las Bases de Régimen local (artículo 10, Ley Constitutiva de las Cortes), no siendo por razón de urgencia, y aun así, la Comisión especial, constituida a tenor del artículo 12 de dicha Ley, puede llamar la atención de la Comisión Permanente de las Cortes si advirtiera materia de contrafuero (artículo 13, Ley de las Cortes).

Respecto de un precepto como el que recoge la Base 56, párrafo final, de la Ley de Régimen local de 17 de julio de 1945, su deslegalización tiene que ser expresa desde luego.

Toda norma general que venga inserta en una ley aprobada por autorización, no prevenida en las bases legales, sólo tiene rango reglamentario (3).

En análogo sentido se refiere el artículo 11, 3, de la Ley General Tributaria, por el que nunca puede derogar una ley básica formal un precepto reglamentario, pues entonces adolece de vicio de nulidad absoluta.

La inserción de un texto que infrinja toda ley de autorización de bases, es impugnable en vía jurisdiccional por las Asocia-

(2) Aunque el preámbulo del Decreto legislativo de 11 de julio de 1963 se refiere solamente a haber sido oído el Consejo de Estado, sin indicar si en Pleno o en Comisión permanente, es de suponer que lo habrá sido de su Pleno (V. GoNZÁLEZ PÉREZ, "Régimen especial de Madrid y Barcelona», Revista de Administración Pública, núm. 25, pág. 333).

(3) Vid. Garrido Falla, aLa fiscalización de los Decretos legislativos por la Jurisdicción Contencioso-administrativa», Revista de Administración Pública, número 60, septiembre 1969, pág. 14, y Revista de Direito Público, núm. 15, noviembrediciembre (San Pablo, Brasil), 1971, pág. 23; Garcfa DE ENTERrfa, Discurso de ingreso en la Real Academia de Legislación y Jurisprudencia, versado sobre «Legislación delegada y Control judicial», 1970, págs. 141-43. 
ciones o Corporaciones representativas de afectados lesionados en sus intereses directos, en virtud de lo dispuesto en el artículo 28 de la Ley de lo Contencioso; empero transcurrido el plazo de dos meses, a partir de la publicación del Decreto legislatił́o, parcialmente ilegal, como el texto comentado de la Ley especial de Madrid, no puede ser ya impugnable por vía general erga omnes, sino sólo por quienes tengan interés en mantener el acuerdo municipal anulado ex oficio (miembros de la Corporación anterior o quienes hayan adquirido un derecho subjetivo por el acto administrativo anulado por la Corporación local), al ser aplicado el texto ilegal que otorga facultades para anular el acto administrativo que infringió el artículo 369 del Decreto legislativo de Régimen local de 24 de junio de 1955, que es reproducción de la Base 56 de la Ley referida de 1945.

\section{PUNTO DE VISTA POLITICO DE LA REVISION ADMINIS- TRATIVA DE LOS ACTOS DE LA ADMINISTRACION LOCAL}

¿Por qué no se equipara la Administración local a la Administración central, a los efectos de declarar nulos de pleno derecho ex oficio los actos administrativos, al menos cuando son manifiestamente ilegales?

De una parte, si el acto de la Administración local es manifiestamente ilegal no quedará inmune, porque, con arreglo al artículo 391 de la Ley de Régimen local: "Las Autoridades y Corporaciones locales podrán interponer ante el Tribunal provincial de lo Contencioso-administrativo (hoy Salas de las Audiencias Territoriales), recurso contra sus propias decisiones, previa declaración de la correspondiente lesividad para los intereses económicos, siempre que dichas decisiones impliquen, además, vulneración de un derecho administrativo de la referida Corporación o violación de leyes o disposiciones administrativas que motive recurso de anulación», lo cual tiene su adveración en el artículo 56, 1, de la Ley de lo Contencioso-administrativo en la siguiente cláusula general: "Cuando la propia Administración autora de algún acto pretendiere demandar ante la jurisdicción contencioso-administrativa su anulación, deberá previamente declararlo lesivo a los intereses públicos de carácter económico o de otra naturaleza en el plazo de cuatro años a contar de la fecha en que hubiere sido dictado.» 
De todas suertes sigue en pie la objeción de que debe equipararase la Administración local a la central.

A ello puede oponerse el argumento de que en la Administración local suele haber apasionamientos políticos cuando acaece la renovación de las Corporaciones que la rigen. El celo de los miembros de la nueva es más político que jurídico.

De esto sé yo algo de mi experiencia como Secretario de un Ayuntamiento de capital de Provincia.

Cuando sobrevino la República en 1931, y por ende el cambio gubernativo - no por elección- de las Corporaciones locales, se desataron los Ayuntamientos en declarar lesivos los acuerdos municipales de nombramiento de funcionarios, de formulación de contratos públicos de Obras y Servicios, con espíritu de pasión política, y si no fuera porque intervenían, con arreglo al artículo 15 del Reglamento para la aplicación del artículo 7, párrafo final, de la Ley de la Jurisdicción Contencioso-administrativa de 1894 (4), los Tribunales provinciales de esta Jurisdicción -hoy Salas especiales de las Audiencias Territoriales- se hubieran cometido muchos desaguisados.

De requerirse el procedimiento determinado por la declaración de actos nulos administrativamente por el artículo 109 de la vigente Ley de Procedimiento administrativo, convertiría en demandantes a los interesados en mantener el acuerdo (funcionarios, contratistas, miembros de las Corporaciones), en vez de demandante a la Corporación local interesada, considerando legitimados, por tanto, pasivamente a los particulares en cuyo favor declaró derechos subjetivos el acto cuya reforma se pretende y a los funcionarios que adoptaron el acuerdo para intervenir en defensa del acto, por lo que incumbiría la carga de la prueba a los particulares recurrentes y no a la Administración demandante, como creo es lo más acertado.

Entonces se pretendería declarar, en un supuesto, nulos contratos de la Administración local, formulados sin subasta o sin subasta y concurso; pero en los que se hubieran cumplido los trámites legales de excepción de tales formalidades procedimentales, en un afán persecutorio de reacción política, que la Jurisdicción contenciosa confirmaría.

(4) Véase el problema político agravado por los Decretos de 20 de abril de 1931 y 15 de abril de 1932. 
Como es más factible que la pasión política se revele en la Administración local, sobre todo en los Municipios, que en la central, a nosotros, desde un punto de vista jurídico-político, nos parece que deben quedar las cosas como están, no permitiendo que la nueva Ley de Régimen local introduzca la facultad de revisar, de oficio, los actos de la Administración local, a fin de seguir el criterio determinado en el artículo 109 y demás concordantes de la Ley de Procedimiento administrativo de 17 de julio de 1958 - y no de otra manera se comporta el Proyecto de la Ley de Bases de Régimen local (5) sometido por el Gobierno a las Cortes Españolas-, revisado por la de 2 de diciembre de 1963.

Pues de otra suerte, si el Tribunal Contencioso-administrativo no anula sino que afirma o confirma el acto administrativo local, no lesivo de derecho $\mathrm{y}$ de intereses, $\mathrm{y}$ no se condena en costas a la Administración recurrida, tiene que soportar el administrado triunfante las costas de un proceso promovido por un espíritu pasional político, porque, si bien hoy no hay partidos políticos, mañana podremos conteinplar asociaciones políticas divergentes en materias públicas locales, y desde luego no se preterirían, de ordinario, luchas nacidas de rivalidades de política de campanario, que puedan llegar a trocarse en organismos de implacable hostilidad las Corporaciones locales nuevas respecto de las antecesoras; y la consecuencia del pleito ganado por los administrados sería la de tener que soportar los gastos de defensa inútilmente y padecer intranquilidades psíquicas, lo que no sería factible de ser actora la Adminstración local, que, como tiene que oir informe de Letrado (artículo 370, Ley de Régimen local), y no siendo nada claro que el pleito prosperase, no aconsejaría la demanda jurisdiccional por lesividad e ilegalidad de acuerdos que la Corporación hubiese adoptado, y de promoverla podrían originarse responsabilidades civiles de los promotores, lo que retraería a los miembros corporativos en adoptar acuerdos para proseguir juicios temerarios.

(5) La Base 2." de dichg Proyecto de Ley sólo dice: «En el plazo de un año, el Gobierno adaptará a los principios de esta Ley las normas contenidas en las leyes reguladoras de los Regímenes especiales de los Municipios de Madrid y Barcelona, textos aprobados por Decretos 1.647/1963, de 11 de julio, y 1.166/1960, de 23 de mayo, respectivamente.

Como se observará, no alude para nada al artículo 369 de la Ley de Régimen local ni a la del 17 de julio de 1945, en cuya Base 56 tiene su asiento el artículo 369 mencionado. 